EPiC Series in Computing
Volume 78, 2021, Pages 148-158
Proceedings of the European Univer-
sity Information Systems Conference 2021

\title{
Digital education during the pandemic: student experience
}

\author{
Anna Pacholak ${ }^{1}$ \\ ${ }^{1}$ University of Warsaw, Poland \\ a.pacholak@uw.edu.pl
}

\begin{abstract}
The paper presents a summary of findings from the student digital experience insights survey carried out among students of bachelor, master and doctoral studies at the University of Warsaw during the Covid-19 outbreak in the winter semester 2020/21. It provides an overview of how students perceive the university digital provision as well as the digital teaching and learning at their courses during the pandemic, when the university was forced to introduce immediate online education with a very limited faceto-face component carried out at laboratory or field classes only.

Students share their opinions on what digital tools were most commonly used at their courses and assess their reliability and usefulness in the education process. They also indicate the advantages and disadvantages of digital education, revealing its potentials and barriers.

In fact, the pandemic emergency teaching circumstances have accelerated the process of the University digitalisation in didactic. The findings of the survey and the experience gained are valuable for identifying which elements of the digital education should be developed further and adapted to the post-pandemic reality within a "new normal".
\end{abstract}

\section{Background information and the university digital infrastructure}

\subsection{Virtual Learning Environment at the University of Warsaw}

University of Warsaw (UW) offers a virtual learning environment for on-line teaching in a form of one common interuniversity platform Kampus (Moodle based) integrated with LMS (USOS) and maintained by the Digital Competence Centre. The unit provides trainings for teachers and e-learning helpdesk to the whole academic community. 
Teachers, however, have freedom in deciding whether it is beneficial to apply it for their course purposes. They may use VLE for fully online courses, blended ones or as a repository for materials and literature. In general, once trained, they find it very convenient as all the course materials, including multimedia, can be embedded in a clear and structured way in one learning environment. Moreover, the system meets well the needs for teaching in large groups. The automation of enrollment, communication via discussion forums and marks migration are also appreciated by users. Integration with the BigBlueButton videoconferencing system has also been installed.

Moreover, an existing e-mailing system at the University of Warsaw is maintained under Google. This was of great benefit, especially during the Covid-19 pandemic, as teachers quite easily could switch to all Google support tools such as Google Meet, collaborative docs, forms or Jamboard.

There are also faculties at the UW (such as Mathematics or Management) that have set their own Moodle or other platform installations for an internal use; however they do not offer any helpdesk or training support.

\subsection{Emergency teaching during the pandemic (March 2020 - March 2021)}

Covid-19 outbreak has caused a huge disruption in education. Teachers have been compelled to online teaching provision in a very short time. That immediate change was both demanding and stressful, particularly for those who have not dealt with online education so far.

Although a technical digital infrastructure has been already set at the UW, it was not sufficient enough to enable massive online education. In such an emergency situation a quick adaptation of empowering servers took place in order to ensure access to digital education for the academic community, including e-exams and recruitment. Massive trainings for teachers have been also delivered.

In total, according to the data obtained in March 2021, the number of e-courses at the Kampus platform increased to 7814 (seven times more as on average) and there are already 2231 teachers running the courses on the platform for 67705 users altogether.

\section{The online survey}

In order to explore student digital experience during the pandemic an online questionnaire has been distributed among students of Bachelor, Master and doctoral studies (aged 19-31) during winter semester 2020/21. It has been filled out on a voluntary basis. 45 anonymous replies have been collected from various faculties such as Biology, Economy, Physics, Management, Geology, Law, Psychology, and Mathematics. 


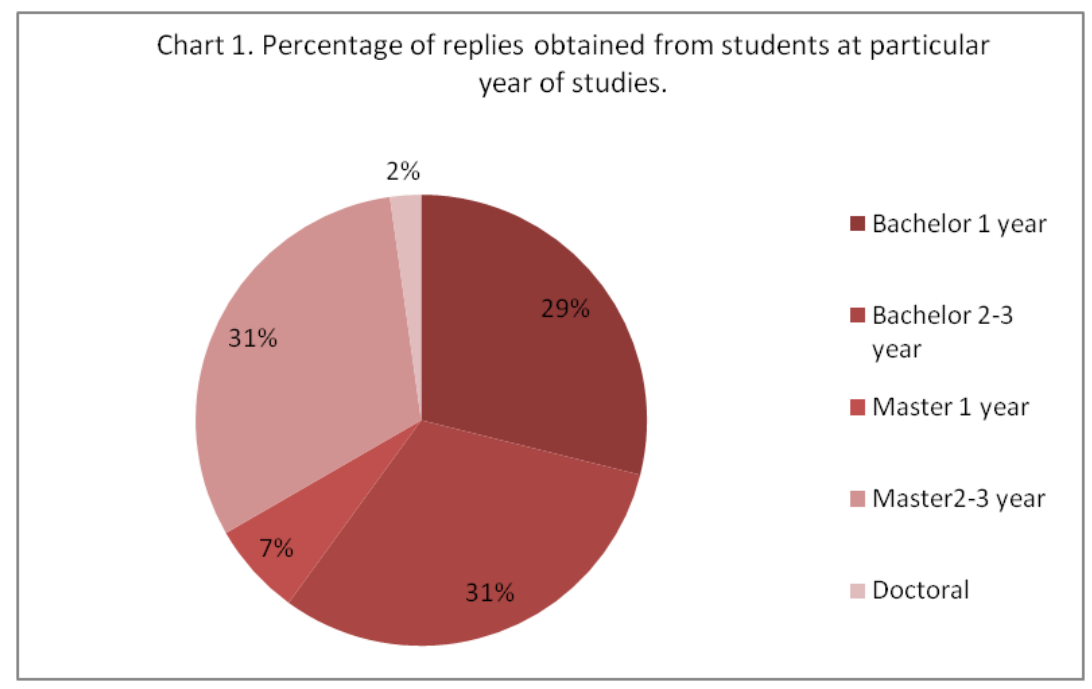

Chart 1. Percentage of replies obtained from students at particular year of studies.

The survey contained both closed (multiple choice) and open questions referring to:

Technology Enhanced Learning in the courses they have taken, evaluation of the tools used at their courses,

Individual digital learning habits, advantages and disadvantages of online education,

online teaching methods worth continuing in post-pandemic reality.

The questions focused on tools and methods assessment from an individual perspective in order to understand better the end user experience. Their usefulness and potential areas worth to be applied in curriculas were asked to be indicated.

\section{Key findings}

\subsection{Means of emergency teaching \& assessment}

The main and basic asynchronous communication channel between teachers and students was emailing received by all students taking part in the survey (Chart 2). Commonly the announcements have been released at the forums embedded at the e-courses on the Moodle platform, via chat or Google Classroom posts, and rarely by Facebook group or directly from USOS (LMS system). 


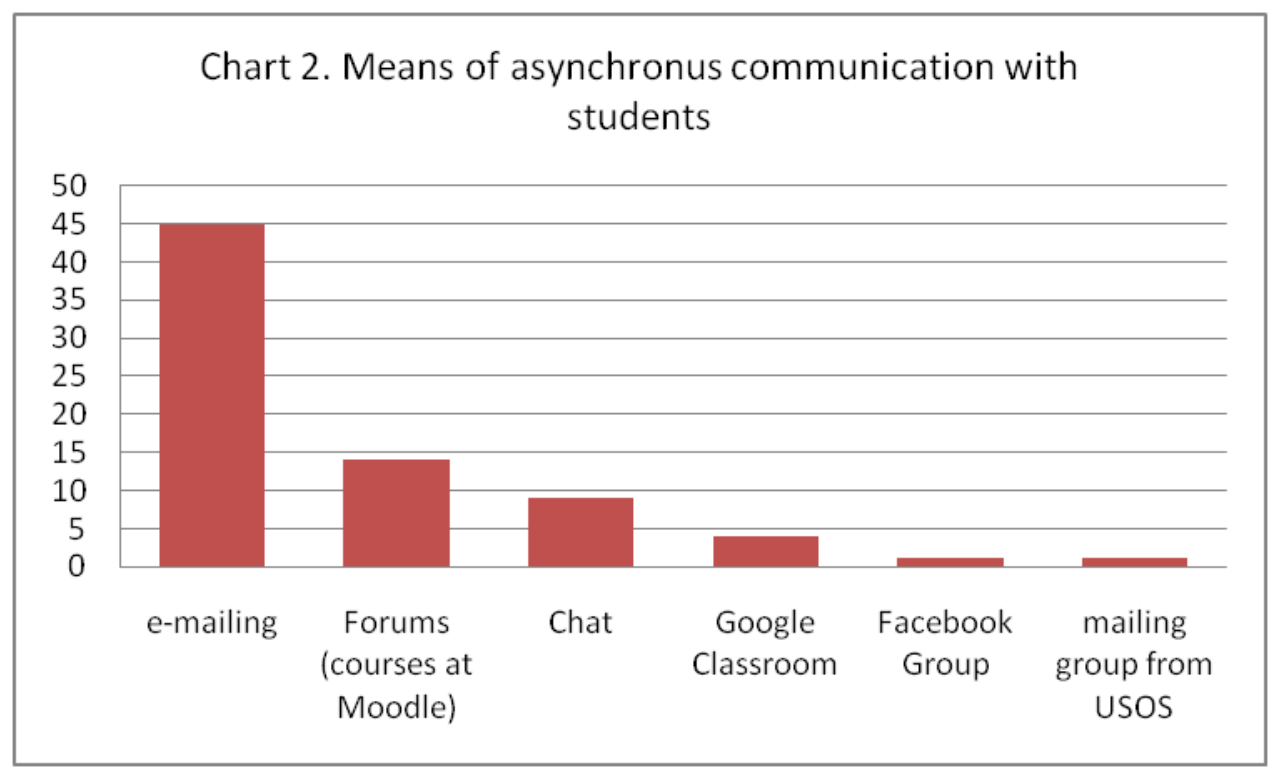

The dominating forms of teaching at the UW were live lectures via videoconferences. Among the videoconferencing systems such as Zoom, BigBlueButton, Google Meet, MS Teams, Skype, Webex or other, the most popular were as it follows ( $\%$ of students who indicated their lectures have been carried out via this video conferencing tool):

1. Zoom (95\%)

2. Google Meet (88\%)

3. BigBlueButton (46\%)

4. MS Teams (39\%)

In general, students express satisfaction from these VC tools and $51 \%$ rate them as good and $29 \%$ as very good.

Some of the lectures were recorded and available for students on the e-learning platform throughout seven days or shared via email. This practice has been much appreciated by students, as it lets them learn in asynchronous mode giving more flexibility in learning at their own pace.

Breakout rooms were commonly used by smaller groups at the courses involving an element of practice. Interactive whiteboards were of particular value, especially for mathematics. The most appreciated ones were: Miro, Jamboard, BigBlueButton, and Zoom.

Most commonly, course materials have been embedded at the Kampus platform (Moodle), shared at the Google Classroom or MS Teams. Those platforms also served well for student knowledge assessment (tests, essays, project work, on-line oral answer, etc.) during the course.

As for the final digital written exams, the special Moodle installation has been launched Kampusexams. It proved to be a very reliable and efficient tool. There were over 2200 exams carried out via the platform (from March 2020 to March 2021) for groups of a few hundred students at the same time. 


\subsection{What forms of teaching have proved successful}

Students have been asked on what forms of teaching have proved successful and why.

It occurs, that lectures in a form of videoconference met the expectations of students. Most of them pointed out, however, that lecture recordings should be available from afterwards as they find it very convenient for their learning, similarly to other materials such as presentations or texts.

Moreover, some of them emphasized, that the video-lecturing form could be continued in a postpandemic time and only practical parts is smaller groups could be held in class.

Students appreciated all forms of being activated by teachers involving group collaborative tools, but also individual assignments. Unfortunately, very few teachers tried to engage students in attractive way such as gaming or sharing simulations.

When asked on what digital teaching activities proofed to be successful in knowledge acquisition, a frequently repeating reply was that it is online collaboration in a small group and whiteboard sharing. There have been also other activity forms indicated, such as:

- $\quad$ interactive discussion/video chat

- $\quad$ games, simulations, polling

- $\quad$ taking notes/sharing notes at Google drive by the group

- $\quad$ recorded lectures

- $\quad$ team work assignments

- tutorials

- mini-essays

- $\quad$ online tests.

These prove a bunch of activity methods should be applied that are targeted to various modalities of the learners.

\subsection{What digital services met the expectations of the learners}

Students were requested to identify the most useful digital service delivered by the university and explain why they chose that one. $30 \%$ of replies pointed to Kampus (Moodle platform) considered as the most user friendly in terms of clear structure of materials in one digital environment together with communication and assessment system (online tests, e-exams, e-assignments).

There were also other e-services commonly appreciated, including:

- $\quad$ USOS mobile app (LMS mobile)

- $\quad$ E-library service (e-textbooks)

- $\quad$ Google drive under student e-mail

- $\quad$ access to MS Office 365

- $\quad$ free licenses for relevant software, in example: Lex, Wolfram Mathematica 
- recorded lectures.

Many of the above have been pointed as very supportive, in general, in learning, even before the Covid-19 pandemic (Pacholak, 2019, 2020, Thoring, Rudolph, Vogl , 2017).

Consequently, when asked what kind of digital support they would like to receive from university in a future, they mostly pointed to:

- more e-textbooks and access to literature online

- free licenses for dedicated software

- free MS Office available offline.

\subsection{Main common concerns}

As long as the internet connection was good enough at both lecturer-student sides. the online teaching and learning could be carried out. Nevertheless, not all learners have sufficient socioeconomic conditions for home learning. Some of them struggled not only with lack of stable internet connection but also with lack of privacy, in terms of learning space, or having no constant access to digital devices on their own. This was a real barrier for some students and caused both frustration and an arising feeling of social exclusion. Digital education in such conditions has no chance to be successful, and it is considered as a disadvantage, thus these students opt for fully face-to-face in class teaching.

Paradoxically, there were also students with difficulties in social face-to-face relations or distracted when in a crowd, and they discovered fully remote education as a perfect environment for their learning. Remote teaching has been found as an advantage also to those who combine their learning with work. It significantly facilitated the balance between both. Consequently, this proves there should be a space left for individual approach and flexibility in forms of teaching.

At a course level, many teachers have not been ready for quick transition to digital teaching, thus they were trying to run classes in the same way as in the classroom via videoconferencing systems. In many cases that form of "emergency remote teaching" simply has not worked and did not engage students. As an example, according to Chart 3,69\% of teachers have never involved simulations or gaming into learning process at a course. Surely, this is not the essence of their work, however the quick change of teaching conditions has not been followed by adaptation of new digital means serving to obtain the educational goal. 


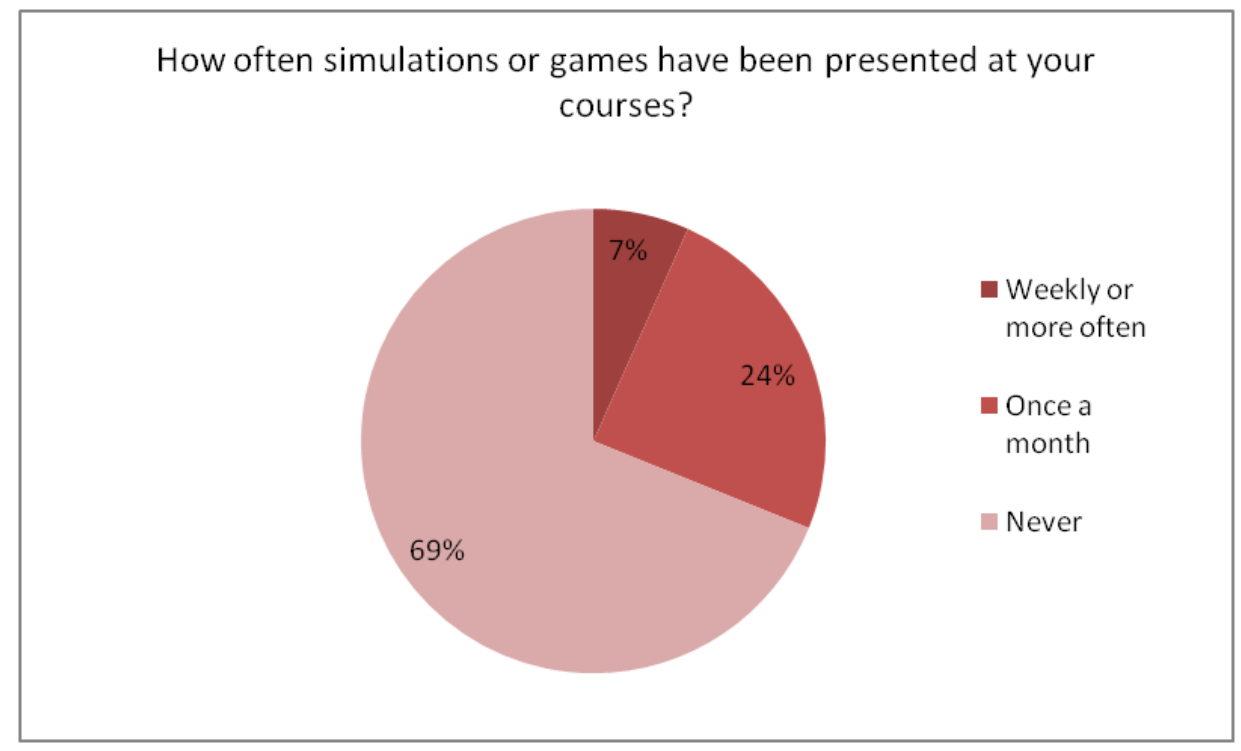

Chart 3. Percentage of answers on how often the simulations or gaming have been involved into learning process at a course.

\subsection{Recommendations from students}

Among the university services, students perceive very beneficial for their learning, there are: ecourses at the e-learning platform (Moodle), USOS mobile app (LMS mobile), E-library service (etextbooks), Google drive and collaborative tools, access to MS Office 365 and free licenses for dedicated software.

The dispersed means of teaching (Zoom, Teams, Google tools) caused a lot of confusion, especially for freshmen. One learning environment would be very much of help for organising the learning process.

Video recordings from the lectures available any time have been recommended as a practice facilitating learning process.

At a course level students expect clear structure and regularity in sharing the materials, predefined forms of assessment, interaction and activation. What also matters is creating a sense of belonging and to motivate students to acquire knowledge.

In the opinion of $76 \%$ of students, a hybrid/blended-learning should be continued in postpandemic education, as it saves time and gives some flexibility to students to acquire knowledge at their own pace (Chart 4). Many of students pointed out that it should refer to theoretical classes which could still be run online, whereas the parts including practical element, in smaller groups should definitely be carried out face to face. 


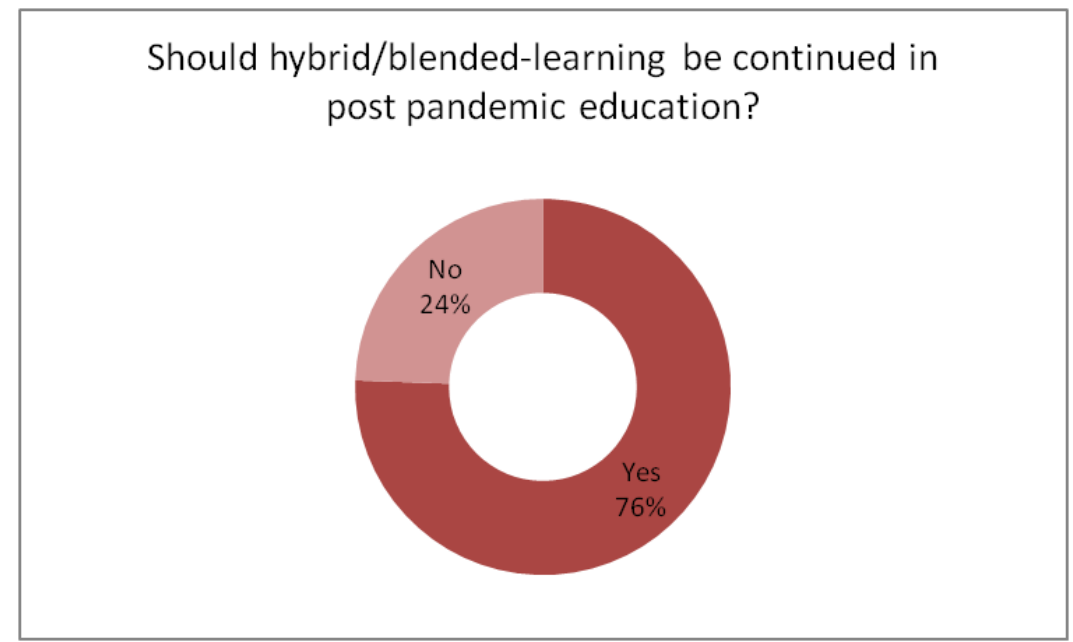

Chart 4. Percentage of positive and negative answers on the question if a hybrid/blended-learning should be continued in post-pandemic education.

The proportions of online learning vs. face-to face learning depend on the subject being taught, individual preferences and socio-economical situation of the learners. According to $53 \%$ of students, the virtual (online) learning component should range between 30\%-50\% within the whole educational process, and no one wanted it to have fully or $90 \%$ online (Chart 5).

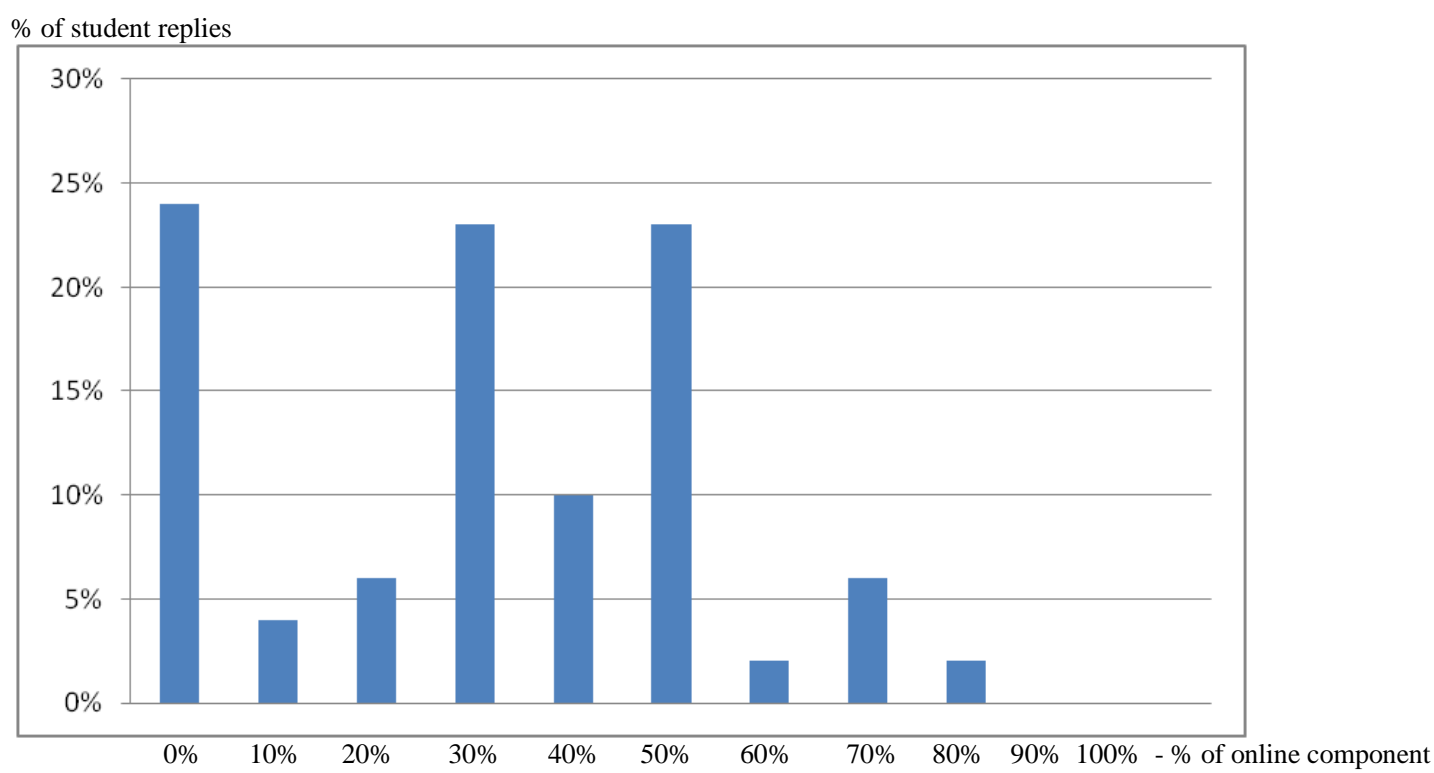

Chart 5. Percentage of students' replies indicating the proportion (from $0 \%$ to 100\%) of online component that could be adopted to the entire learning process in the future. 


\section{Conclusions}

The Covid-19 outbreak crisis has challenged higher education institutions in many unexpected ways, what brings both challenges and opportunities, particularly in relation to the digitally enhanced learning and teaching. According to the Jisc insight (Killen, Langer-Crame, 2020), the rapid move to remote learning has amplified the need for pedagogical learner-centred approaches with technologyenhanced learning and teaching as an integral aspect of learning design.

Although there are many studies focusing on the digitalisation in the field of HE, they are often designed as a quantitative study and therefore allow only for a very general view of the topic (Dahlstrom et al., 2015, Gierdowski et al. 2020).

The 2020 Jisc report is of particular value as it contains the key findings on student digital experience from the pandemic period (Killen, Langer-Crame, 2020). Even though an individual institution requires an insight into its own existing digital infrastructure, quality of services provided and end-user experience for the relevant further strategic planning. Thus, a survey among students of the University of Warsaw has been run.

According to the survey carried out among the students of the University of Warsaw in 2020/21, they highly appreciated one Virtual Learning Environment. Otherwise, they are confronted with an excess of tools and organisational chaos leading to cognitive overload, since they have to learn how to use all the functionalities and to look for their course materials at many platforms.

The most important barrier, for some of the students, was a poor quality of internet connection that was seriously damaging their quality of learning and performing. The other one, were the conditions of learning space, that in case of remote learning requires a minimum of privacy, which not always could be met, depending on the socio-economic situation. Access to digital devices enabling online education has also been of important concern for some students and a real barrier in studying that was not easy to overcome. To some extent, those two factors lead to educational exclusion. Another story is however, how students deal emotionally with isolation caused by the pandemic, as their reactions vary a lot among individuals and influence on their learning as well.

Online learning requires an appeal to the self-regulating capacity of learners. Students need to learn how to plan, how to manage their time, how to set goals and how to avoid distraction. This should be addressed within their curriculum.

If the fundamental conditions for online education are met (fair internet connection, access to digital devices, privacy of the learning space), students praise the access to digital materials. In their opinion, in a post-pandemic reality, many lectures could be continued in on-line mode with the possibility of access to the recording later on. This saves their time they have to devote to commuting and lets them study at their own pace.

When asked on the proportions of the digital component in blended learning, the most frequent replies (indicated by 53\% of students) pointed to 30\%-50\%. Interestingly, according to the replies obtained, $85 \%$ of students declared they would like digital technologies (e.g. online material 
repositories, mobile applications, polling) to be used in their face-to-face classroom activities after the pandemic.

Likewise in previous years, better digital collaboration within the students' group, interactive engagement at a class and possibility to access the specialized software within a free license delivered by the university are very welcome by students (Thoring, Rudolph, Vogl, 2017, Pacholak, 2020).

Naturally, there is no one-size-fits-all solution, and it is really up to the teacher to balance the didactic means (either traditional or digital) in order to obtain its educational goal.

Nevertheless, the feedback information obtained from students is crucial for further digital education provision. Even though the survey was run for the University of Warsaw purposes, the outcomes deliver an overview of young people's digital literacy skills and approach towards digital education. The results can be scaled with the other datasets, serving well for shaping the next steps in digital transformation. This is also the momentum of sharing of crisis-related good practices among universities, which this paper aims to.

\section{References}

1. Dahlstrom, E., Brooks, Ch., Grajek, S. Reeves, J.(2015). ECAR Study of Undergraduate Students and Information Technology, Research report 2015. Retrieved February 2, 2021, from https://library.educause.edu/resources/2015/8/ /media/24ddc1aa35a5490389baf28b6ddb3693.ashx

2. Galanek, J., Gierdowski, D. (2019). ECAR 2019 Study of Faculty and Information Technology. 2019 EDUCAUSE research report. Retrieved February 2, 2021, from: https://library.educause.edu/resources/2019/12/2019-study-of-faculty-and-information-technology

3. Gierdowski, D., Brooks, Ch., Galanek, J. (2020). 2020 Student Technology Report: Supporting the Whole Student, 2020 EDUCAUSE research report. Retrieved February 2, 2021, from: https://library.educause.edu/resources/2020/10/2020-student-technology-report-supporting-the-whole$\underline{\text { student }}$

4. Killen, C., Langer-Crame, M. (2020). Student digital experience insights survey 2020: UK higher education findings. Jisc, Retrieved February 2, 2021, from: https://www.jisc.ac.uk/sites/default/files/student-dei-he-report-2020.pdf

5. Langer-Crame, M., Newman T., Beetham H., Killen C., Knight S., (2019). Digital experience insights survey 2019: findings from students in UK further and higher education. Jisc, Retrieved February 8, 2021, from: https://www.jisc.ac.uk/reports/digital-experience-insights-survey2019-students-uk

6. $\quad$ Langer-Crame, M., Killen C., Francis J., Beetham H., Knight S., Newman T. (2019). Digital experience insights survey 2019: findings from teaching staff in UK further and higher education. Jisc, Retrieved February 8, 2021, from:_https://www.jisc.ac.uk/reports/digital-experience-insightssurvey-2019-staff-uk

7. Pacholak, A. (2019). Digital university: student perspective, European Journal of Higher Education IT, issue 2019-1, Retrieved from: https://www.eunis.org/download/2019/EUNIS_2019_paper_84.pdf

8. Pacholak, A. (2020) Digital university from student perspective: a step forward, European Journal of Higher Education IT, issue 2020-1, Retrieved February 18, 2021, from: https://www.eunis.org/download/2020/EUNIS_2020_paper_10.pdf

9. Thoring, A., Rudolph, D., Vogl, R. (2017). Digitalization of Higher Education from a Student's Point of View. EUNIS Book of Proceedings 2017, pp. 279-288. Retrieved February 18, 
2021 from: http://www.eunis.org/eunis2017/wp-content/uploads/sites/10/2017/07/EUNIS2017_Bookof_Proceedings 1. pdf

\section{Author biography}

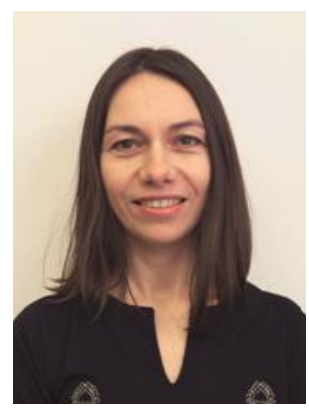

Anna Pacholak, MSc, works in the Digital Competence Centre, University of Warsaw. She has been engaged in a number of various educational projects involving e-learning and digital teaching. Her main scope of interest is focused on open access education, digital education, motivation spects in the learning process, new technologies for education, psychology of learning and positive psychology in the education process.

Author of scientific papers; EDUCAUSE Annual Conference reviewer.

LinkedIn: https://www.linkedin.com/in/anna-pacholak-947251147/ 